\title{
2. Sustainability comes naturally at the purpose-driven Rocky Mountain Soap Company
}

\section{Pramodita Sharma, Sanjay Sharma and Alexa Steiner}

Karina Birch and Cam Baty are the husband and wife team behind Rocky Mountain Soap Company (RMSC), a leader in the Canadian natural personal care industry. Based in Canmore, Alberta, Karina and Cam have owned and operated this first-generation family business for almost two decades. Cam grew up in Manitoba, Karina in Alberta and they met in the 1990s at an Arctic fishing lodge in a remote part of Canada. At that time, Cam was managing the lodge and hired Karina over the phone:

It all started at that fishing lodge. The lodge really attracted like-minded people with connections to the natural world. I grew up on a family farm, and Cam grew up outdoors, hunting, so we've both been connected to nature throughout our lives. Our common connection to land, adventure and the outdoors is a big reason why we're now based in Canmore. (Karina Birch, Chief Executive Office)

Each with a business degree, Karina's from the University of Alberta and Cam's from Ryerson University in Toronto, in late 1999, the couple was looking for an opportunity to start a business. A chance gift purchase, from Cam to Karina, of soap from a local grocery store, spurred the opportunity that would define the couple's future. Owning a soap business was not necessarily the plan, but Karina and Cam have been paving the way as a sustainable family business since they took a risk and bought the small business two decades ago:

Blind optimism fueled the first few years of the business, but perseverance and a great team helped us grow the company to what it is today. (Karina Birch, CEO)

Handmade products with a limited number of 100 percent natural, simple ingredients, is the mantra of RMSC. The foundation of the business has always stemmed from the couple's core purpose: to love nature and encourage more educated consumers to choose a toxin-free lifestyle. 
Since 2000, Karina and Cam have grown their employee base to 180, with products being sold online and in over 100 retail locations. Currently, the company's annual growth rate is 15 percent, growing even more rapidly than the Canadian conventional beauty industry, that grew 9.4 percent as a whole, in 2017. ${ }^{1}$ All the while, the couple has grown its nuclear family to five, with three children, now ages 14,11 and 8 . They have taken time to explore the world with their kids, leaving Canmore twice for extended trips to spend a few months in Europe. Taking this time off to enjoy with their family has helped to strengthen their leadership team and business:

When we made the decision to travel with our kids, we wanted to test and see if the team could run the business effectively without us. They succeeded! The business continued to grow in our absence. (Cam Baty, Chief Operating Officer (COO))

They were still checking in, so they weren't totally gone. The time went by quickly, but there was something really nice about when they came back - they are the business. Though it ran just fine while they were away, it was nice to have their physical presence back when they returned. (Jane Doyle, Retail Director)

A strong mission is the core of the company. Purpose-driven companies have proven over time to continually outperform their peers. ${ }^{2}$ While continuing to build their purpose-driven business, Karina and Cam hope to pass along their beliefs and instill the love for the business and the natural world in their children.

\section{COMPANY HISTORY}

Before Karina and Cam purchased the company, it was a tiny, single-employee, home-based business that had been founded in Canmore three years earlier. The previous owner had just opened a small 450 square foot retail location in downtown Canmore and annual sales were about 80,000 dollars. Karina and Cam contemplated purchasing the company in December 1999, after Cam had discovered the product in a grocery store in Edmonton and gave it to Karina as a gift. She loved the product and they became regular customers of the brand. They became loyal followers and began even gifting RMSC products to their friends. Upon receiving consistent raving feedback, they recognized that the product was so good that people were hooked! Not long after, they started looking into the company as a potential business opportunity.

At the time, the couple was dating but lived in different cities. They had an interest in building a business together as they both had completed undergraduate degrees in business just a couple of years prior. Purchasing an existing 
business was an option, as was starting their own, and thus they saw the opportunity that this small company provided:

We phoned a friend in Canmore, who happened to be the landlord for the existing retail location. We wanted to ask him what the town needed because we wanted to open a business in Canmore that filled a need. He put us in touch with the woman who owned Rocky Mountain Soap Company. She was looking to sell, so we went in to see it, and one month later we owned it! (Cam Baty, COO)

The entire purchase process took less than six weeks. During this time, Karina and Cam recognized the immense potential of the product but were also acutely aware of the existing deficiencies, such as the packaging, marketing and sales strategy. Despite these deficiencies, they knew why this product was so valuable; it was different from any other personal care product that was available at the time. Natural products were not popular or trendy in 2000; it was a niche market, and Karina and Cam had the foresight to recognize what was to come. The couple's passion for the natural world and its benefits, as well as Karina's background in aromatherapy, lent itself well to the industry they decided to enter.

Knowing that they had an incredible product was not enough. The business was losing money in the years before the purchase and their accountant advised Karina and Cam not to buy the sinking ship. Nevertheless, they decided to take a risk, and within a year, they had turned the business around. Karina and Cam purchased the store for about 45,000 dollars with a combination of personal savings, a 15,000 dollar bank loan and a personal line of credit. The initial founder of the company stayed on for about two weeks to hand over the business and provide them some training, but after that, the business was up to Karina and Cam.

One sticking point for the couple, when they bought the company, was the marketing of an "all-natural" product that was not truly all natural. At that time, some of the products contained artificially fragranced oils that rendered the product less than 100 percent natural. For example, their berry scent was their top-selling scent across the product line at the time, but it contained a fragrance oil that was not 100 percent natural. Karina and Cam sat down with their employees to discuss this issue. In the early 2000s, no one in the industry knew how to formulate a 100 percent natural personal care product, mostly because saying that a product had 85-95 percent natural ingredients had proven to be "good enough" for consumers. As most customers did not ask questions about ingredients, brands did not have to adjust themselves to demands for transparency, as is the case now. Most of RMSC's contracted suppliers and chemists did not support going 100 percent natural. Karina and Cam faced a lot of pressure to follow the prevalent industry standards, but their 
own beliefs and a strong support from their employees led them to reconsider their product formulations to achieve 100 percent natural ingredients. This led to the discontinuation of some of the company's most popular products. They did so based on their core principles even though it was clearly not the smartest financial decision as their most popular products were the chemically fragranced ones:

We were tiny, and terrified about the impact removing that scent could have on our sales. In the end, it actually did not hurt us. It just increased the trust our customers had in us. (Cam Baty, COO)

Decisions like these are the bedrock that a company stands upon. Even though to this day there is debate in the personal care industry regarding the necessity of 100 percent natural formulas, ${ }^{3}$ Karina explained the rationale for their decision as follows:

Whether it was mashed avocado on my face or an egg in my hair, I've loved experimenting with natural ingredients since I was a little girl. I have always believed that if it came from nature it was the best you could get. I believe that the earth provides more than enough natural ingredients to give us beautiful and healthy skin for life. I believe that body care should provide more than a sweet-smelling experience, it should be beneficial to our health and our psychological well-being. I believe that parents deserve peace-of-mind when choosing products for their families. Shopping for skin and body care should be a purely joyful experience.

Today, our industry uses over 85,000 chemicals and only a fraction of them have been tested for their long-term effects, I don't think that's good enough, and our industry needs to change. It's my personal vision, and the mission of our company to be unwavering in our commitment to toxin-free, so you can shop with the freedom of knowing that everything we make is safe and good for you. (Karina Birch, CEO)

Having made the commitment to make 100 percent natural products and support a toxin-free environment, RMSC adopted a patient capital strategy of investing in further research and development $(R \& D)$ for natural product formulations. However, to remain competitive in the marketplace, it made the difficult decision of maintaining the same pricing strategy, while also trying to maintain production costs.

Much to Karina and Cam's surprise, loyal customers praised them for making that decision and appreciated the evolution of the brand to be even more honest than the market demanded, and go above and beyond industry standards:

Karina actually overheard some customers talking about this change on the street outside the store. They were praising us for the decision we made. To hear that was 
really validating that there really was an audience for the mission we were sticking to. (Cam Baty, COO)

To support their efforts, their customers purchased more of the truly all-natural products and began recommending the company's products to others. Sales began to increase, energizing RMSC to double up its efforts towards 100 percent natural product development:

Especially living here in the Rockies, we are constantly reminded how fragile the environment is and we want to help embrace and celebrate it. (Karina Birch, CEO)

\section{THE NATURAL PERSONAL CARE PRODUCTS INDUSTRY}

Globally, the organic and natural personal care market was estimated at 13.33 billion United States dollars in 2018. The projected compound annual growth rate is 9.4 percent from 2019 to 2025 . North America leads in this category and the trend is expected to continue over the next six years. Increasing consumer awareness is the driving factor for the demand for these types of products. Consumers are becoming more aware of the benefits of natural and organic products in comparison to chemical or synthetic alternatives, and thus the demand for personal care products has increased. The rising desire for environmentally friendly and cruelty-free products is expected to continue to increase product demand. ${ }^{4}$

Kline Research conducted a study in 2016 that concluded a growing number of consumers are willing to pay a premium for products that are natural or perceived as natural. Realizing this, large cosmetic companies have begun to spend significant dollars on R\&D to develop new organic product offerings and are trying to play in the natural space. ${ }^{5}$ Because of this recent focus from larger companies, the natural personal care market has become a focus of the industry over the past few years. This trend is not expected to slow, as consumers become more educated and pay more attention to the ingredients that they are using on their bodies each day.

Larger personal care companies that have begun to change their strategy toward more environmentally friendly operations are focusing their efforts on strategic acquisitions of natural and sustainable companies to learn, build expertise and add natural lines of products. With evolving consumer consciousness, these larger companies are looking to gain further core competencies in ethical production. According to CB Insights, 62 privately held beauty companies were acquired in 2016, 38 percent more than the previous year. In recent years, Clorox purchased Burt's Bees, and Colgate acquired Tom's of Maine. These are just a few examples of the significance of the strategic 
acquisitions in this market. Bigger businesses are making these power plays for sustainable businesses to acquire the knowledge and expertise of smaller firms. The larger companies are continually evaluating what new brands could strategically fit within their portfolio and add value to the core competencies of the business. ${ }^{6}$

The current emphasis on all-natural and organic beauty products has opened an opportunity for new entrants to emerge in the personal care industry with better versions of products catering to consumer needs; however, with the entry of these new companies, it has become increasingly more difficult to create a brand with a solid reputation, and achieve economies of scale. Capturing significant market share in this industry is a challenge for smaller companies with smaller budgets to spend on marketing and advertising. Constant innovation and investment in technology are necessary. Small-scale competitors, such as RMSC, create value-added products and have gained deep customer loyalty, and hence have continued to gain market share. ${ }^{7}$

\section{OPERATIONS}

When asked about the structure and governance of RMSC, Cam Baty noted:

The first person we hired was a woman named Judith, who we hired in 2000 . She worked part time in retail and part time in production. It was all six of our hands-on deck back then. After about a year, retail separated into its own department and Judith went on to manage that area. After retail and production employees, our next areas that we hired for were shipping and accounting. We were figuring it out as we went, and now we have a thriving employee base with a little bit more structure.

While functioning as co-entrepreneurs early on, Karina and Cam eventually agreed that Karina would be the CEO and Cam would be the COO. Cam explained how this decision came to be as follows:

When we bought the company, I was working elsewhere. Within nine months of owning RMSC, I was full time here. Ten years later, after we had kids, Karina was coming back to work full time. She had worked during the early years we had kids, but in 2012 she came back full time. At that time, we had a different CEO, and Karina came back to manage that person. I was working on other projects around that time as well. In 2013, we both decided that we both wanted to be back at RMSC full time and we changed the structure to reflect more like what you see today. We knew we needed a formalized structure in case a difficult decision needed to be made, so that's why Karina is CEO. At the end of the day, titles don't matter to us that much. It's a really collaborative environment and we all work together to achieve what we need to every day. (Cam Baty, COO) 


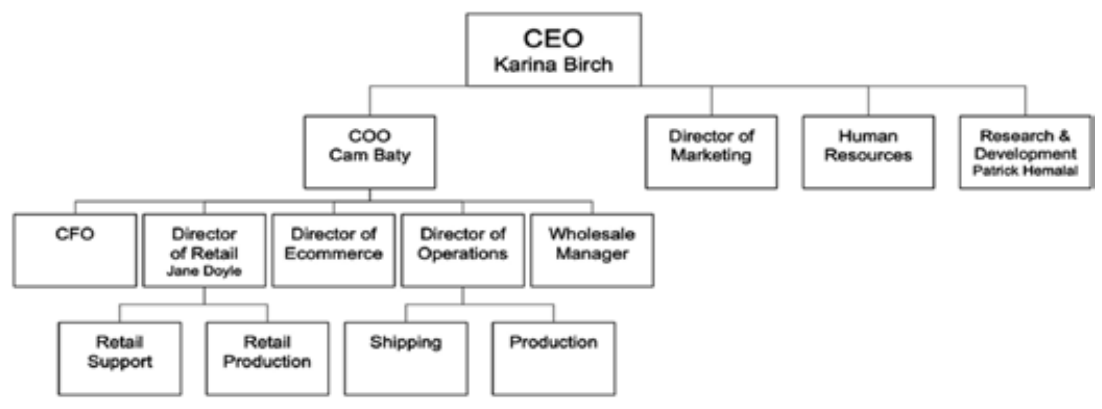

Figure 2.1 Rocky Mountain Soap Company organizational chart

The structure of the company is simple (Figure 2.1). In addition to the couple as $\mathrm{CEO}$ and $\mathrm{COO}$, the top management team includes the three directors of marketing, human resource management and research and development, all reporting to both Karina and Cam. There are additional directors or managers responsible for operations, retail, e-commerce and wholesale operations, reporting to the $\mathrm{COO}$, Cam Baty. The structure is fairly lean and flat and enables close coordination, for example between retail and production and shipping. Each director has a technical specialist working with them, with the exception of retail, as the retail director oversees all of the retail location managers. The company is currently seeking to hire a vice-president to lead new market development. This experienced professional will help them grow the business both in physical locations as well as online:

Our current web developer started as a soap maker 15 years ago. There's room for upward mobility here and we like to foster our employees' professional growth and support it however we can. Longevity matters to us. Jane, our current Retail Director, has been with us for over 12 years. (Karina Birch, CEO)

With Karina in charge of product development and marketing, and Cam handling production and capital investment, there is a clear division of labor and responsibilities. Although there is general alignment of values and overarching vision, at times there are disagreements among the leadership. RMSC values an inclusive decision-making process and holds monthly board and leadership team meetings where important decisions are discussed. This team includes the CEO, COO, chief financial officer (CFO), head of R\&D, director of marketing, director of retail, web strategist, operations manager and some- 
times the product innovation team. Quarterly strategies are determined by this team and are communicated to all employees:

Ultimately, when it comes to stalemate decisions, Karina has the final say as the $\mathrm{CEO}$, though I don't believe she has ever had to use that power. (Cam Baty, COO)

RMSC's goal is to not be a command and control organization and there is an emphasis on a flat rather than a hierarchical organizational structure. There are two human resources employees, one who has quarterly conversations with the executive team about leadership and outlines clear performance management goals for all employees, while the other is a recruiter and works on the hiring process. As with many companies, Cam notes that there is a culture and communication gap between the headquarters and the retail stores; however, the team is actively trying to bridge that gap in creative and authentic ways.

Currently, RMSC has about 180 employees all over Canada. Early on, RMSC developed a core purpose and five values that govern the way it does business and the way it recruits, trains and retains its employees. These values are "Positivitude," "Give it a go," "Be kind," "Customer service is an extreme sport," and "Cultivate team spirit," and are visibly written on the walls of the business (Figure 2.2). ${ }^{8}$

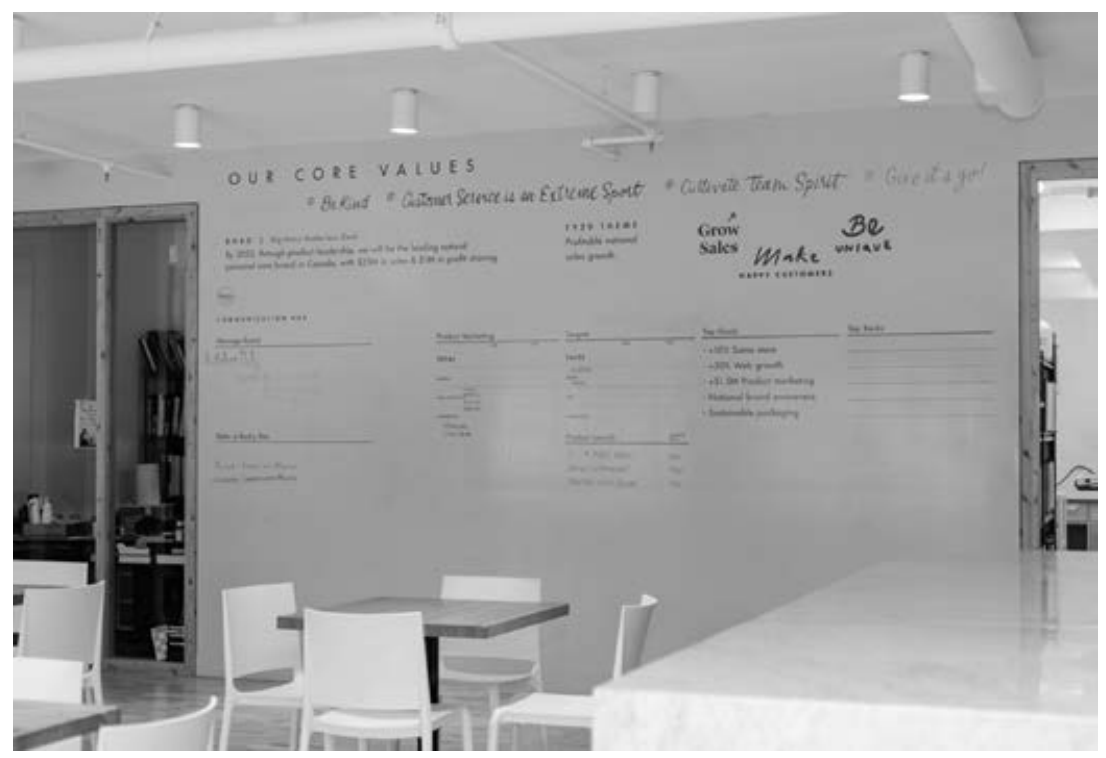

Figure 2.2 RMSC's core values on the wall of its head office 
Karina and Cam strongly believe that their hiring practices and the entire employee experience should reflect these values. Culture is important for them. In their regular Monday morning meeting with all corporate employees, each member shares stories sharing an example or two that links their past week experience to one or more core values. The company's elected "culture mayor" is in charge of creating fun activities and events that keep the core values alive. These events are mostly for corporate employees and retail managers, though some invitations are extended to retail staff:

Our Culture Mayor recently planned our awesome 20th anniversary winter celebration, which was a big holiday party in the new year, with a ski day, dinner, ceremony, and party. She also leads the culture team of five employees who take turns planning the AGM, organizing fun activities in the office like "yoga in the workshop" twice a week, fitness classes like spinning and Crossfit. (Cam Baty, COO)

At RMSC, leadership is about conversation and asking questions. We have a training, onboarding, and leadership book and each new employee is given a copy. There is a strong focus on team happiness and the relationship between company culture and leadership development. We want to foster an environment where people are excited to come to work because they are passionate about the product and feel supported by the company. (Karina Birch, CEO)

Alongside the core values, innovation and wellness are big pieces of the culture puzzle at RMSC. The company also hosts a semi-annual retreat in Canmore for managers and assistant managers of the retail locations. Impressively, the employee turnover rate is less than 10 percent, and exit interviews are conducted with every employee that leaves.

Employees flock to RMSC not just for a paycheck, but for alignment with their values and lifestyle. Jane Doyle, the retail director shared:

I started at RMSC in 2008. Something that has always mattered to me is working with a company guided by purpose. I met Karina and Cam and had a feeling that there was a soul, a purpose to what they were trying to do. When I came to RMSC, there was a culture and environment that encouraged creation and innovation. There was no manual to tell me what to do, so there was an opportunity to create, which was honestly challenging at times. Through that, the purpose of the business never changed - Karina and Cam never swayed from their ethics and that is really important to me. (Jane Doyle, Retail Director)

Patrick Hemalal, the R\&D director, added:

In 2015, while I was working for Colgate Palmolive, Karina was looking for a chief Chemist, someone to lead the research and development area. One of my friends connected me to Karina via LinkedIn. I was in Sri Lanka at that time, where I am originally from. In January of 2015, I came to Canmore for an interview. Karina was 
so nice to me, driving me to and from the bus station. Not long after, in May, I ended up in Canmore. We both took a great risk, that has paid off and I am now a Canadian permanent resident. This is a small company with great potential. I get to work for really nice people every day, in an entrepreneurial environment, with autonomy to make decisions. Plus, I get to live in Canmore. (Patrick Hemalal, R\&D Director)

Over the years, RMSC has received business advice and guidance from outside sources. Cam and Karina looked for guidance from Sean Durfy, former CEO of WestJet. He came on board with RMSC as a mentor for a few years. Cam says they learned a lot from him and his business experience, and now, years later, WestJet purchases RMSC products wholesale for use on planes. ${ }^{9}$ Another, more informal, mentor is Mark Wolverton, the co-founder and CEO of Lush North America. Cam and Karina have called him up over the years with questions about the industry. Lush is a personal care brand, originally founded in the United Kingdom, which was licensed by Mark Wolverton for North America and is based in Vancouver. It is about 10 years older as a company than RMSC. ${ }^{10}$ Cam stresses how important it is to have people to trust as mentors and advisors, both from the industry one is in, and outside of it:

For the last three years or so, we have been working with Glenn Huber, the Founder of Chrysalis Capital. He has extensive experience in private equity, business, and financial advising. He is actually the first member of the advisory board we are in the process of building. That board is in really early stages, currently in the planning phase. He is helping us build it out. (Karina Birch, CEO)

The company has worked with outside consultants in the past particularly to help its branding and marketing efforts, though the preference of Cam and Karina is to do everything they can in-house to ensure consistency and inclusivity.

In terms of the supply chain, sourcing high-quality natural ingredients is a priority for Karina and Cam. RMSC's products use plant-based natural ingredients sourced from around the world. Canadian food distributors are the company's primary source of ingredients, except shea butter that is sourced directly from an organic supplier in Africa:

Sourcing locally is a priority for us and we try to do it whenever we can. It's not always realistic, so we maintain transparent and ethical sourcing practices as we gather ingredients from producers around the world. (Karina Birch, CEO)

RMSC uses all-natural ingredients and prides itself in its transparency and commitment to quality. All ingredients used in its products are 100 percent 
natural, that is, extracted and processed from the earth without any negative environmental impact: ${ }^{11}$

Credibility to our customer is important to us. Early on, we did not have a proper check list for our suppliers. We developed a science-based vetting process for our supply chain with factors including sustainability considerations, process, safety, environmental damage. All of our ingredients must be natural and we were willing to make business sacrifices along the way to ensure that we live up to this commitment to our customers. (Patrick Hemalal, R\&D Director)

All products are made in small batches to maintain freshness and ingredient lists are kept small, usually under 10, to maintain transparency. Simpler formulations and small batches allow RMSC to choose ingredients deliberately for quality and benefits. Unlike conventional personal-care products, fillers are never used in its products. Sustainable sourcing practices are prioritized as well. Organic ingredients are used whenever possible and RMSC prioritizes working with local farmers, growers and wild foragers across Canada. A list of Canadian sources can be found on the RMSC website. The company will not purchase ingredients from any source that has negative impacts on any animals or species habitats or the environment in general: ${ }^{12}$

The evolution of the products has looked more like a circle than a line. (Cam Baty, $\mathrm{COO})$

When they purchased the company, the recipes were very basic and simple, with no water or preservatives. As the product offerings evolved, so did the need for more complex formulas, some involving water. As these complexities developed, external chemists were hired to manage the process and provide recommendations. Eventually, chemists, now led by Patrick Hemalal, were hired internally to continue innovating with new ingredients and formulas:

In more recent years, we discovered that we had an ingredient in our shampoo that just wasn't sustainable. I remember us all sitting together and deciding that the right thing to do was take it out, despite that product accounting for about $10 \%$ of our sales. (Jane Doyle, Retail Director)

Around 2015, the discussion turned to having a mantra of "10 ingredients or less." It was becoming more difficult to stick to smaller ingredient lists as the product lines expanded, and Karina, Cam and their leadership team wanted to make a strong commitment that could guide them through the product innovation process. Thus, the "10 ingredients or less" mantra came about. This 
mantra does not come without its challenges, as it is difficult to make products like face care and body lotion with just 10 ingredients:

Making something look and feel right for the customer is still so important. So this $\mathbf{1 0}$ ingredients or less rule poses an interesting challenge for us with more complex products.

We are working every day to make sure that our products are simple, natural, but also feel and look right for our customers. They also need to preserve well, so that adds an extra layer of complexity! We have incredible professionals working on these innovations. (Cam Baty, COO)

I am a chartered chemist, majoring in chemistry and specializing in natural products. My doctoral degree was to architect biologically active molecules for commercial use. After my PhD, I worked for a few corporations, including Colgate Palmolive, and now I am here, working with natural ingredients all the time. (Patrick Hemalal, $\mathrm{R} \& \mathrm{D}$ Director)

\section{SALES AND MARKETING}

Within the first year of purchasing the company, in 2001, Karina and Cam moved the retail location to Canmore's main street that attracted more tourist traffic. This move proved to be prudent as retail sales jumped from 80,000 to 250,000 dollars within a year. Soon, they opened a second retail location just down the road in another popular tourist mountain town, Banff. This was RMSC's first step in becoming a multi-unit retailer.

The Canadian Rockies are Alberta's most iconic attraction, and one of Canada's most sought-after travel destinations by fellow Canadians as well as international travelers. Canmore's economy, like other Alberta mountain towns, Jasper and Banff, relies heavily on the tourism sector. ${ }^{13}$ Companies like RMSC benefit from the heavy foot traffic on Canmore's main street, the economic center of the town.

The company now has 12 company-owned retail locations throughout western and central Canada, along with a few temporary pop-up stores that stay open for a short period of time as a trial run for a potential long-term location. The products are also sold at over 100 other retailers across Canada. RMSC retail locations in Alberta are quite successful, pulling in the highest number of sales for the company. RMSC has a strong reputation and a loyal customer base in Alberta. Word-of-mouth marketing has been a significant contributor to the success of the business within the province:

Two franchises were opened in the early 2000s. One stayed open for three years, and the other for six. Honestly, we didn't like having franchises and are staying away from that model now. The risk you think you are avoiding, you are still faced with. The responsibility is still there because our name is on the lease, but we don't get the 
reward or the control. Investors have approached us wanting equity in our company over the years, but we just haven't entertained those offers. (Cam Baty, COO)

Expanding outside of Alberta has posed issues. One store and two pop-up shops were opened in Toronto (about 3,500 km away from Canmore), but all closed within six months of entering that market. Because of these lessons, long-term planning for retail locations outside of Alberta is a priority that Karina and Cam are focusing efforts on now:

We've been in Alberta for 20 years, so just through that, we have basic brand awareness. What we've seen in other cities is customers coming in, but they aren't quite sure, so they come in and buy maybe one soap. The trust isn't there yet, so they are seeing if we are who we say we are. Brand awareness takes time. (Jane Doyle, Retail Director)

Natural and organic have become lifestyle terms, reflecting aspirations for good health, hygiene and beauty. The popularity of these products has led to an increase in the distribution channels and ease of access. E-commerce has created even more access to different types of products, allowing companies to reach consumers that were once geographically unattainable, and vice versa. The growing need for convenience and personalization of products has given brands and retailers the opportunity to expand digital footprints and grow their customer base.

RMSC was ahead of the curve with online presence, creating its company website in 2002, though it was never a major priority. Online sales grew slowly but steadily at about 20 percent annually. Less than a decade ago, the company prioritized the website and the potential for increasing online sales. Employees were hired to run e-commerce, and today online sales account for 22 percent of RMSC's business. It is a big growth channel, and the company is starting to now prioritize social media and digital marketing as well. RMSC products are available through the company website, as well as through Canadian online retailer Well.ca, Canada's largest e-commerce provider of natural brands: ${ }^{14}$

I'd say $60 \%$ of our marketing at this point is digital. We are still investing the other $40 \%$ in more traditional methods. The lines are blurry with our marketing budget, as efforts in each category can bleed into the other, though we have increased our online and digital budget significantly over the last couple of years. (Cam Baty, $\mathrm{COO})$

As new technologies provide for more personalized experiences, direct marketing will continue to disrupt the traditional retail distribution network. Direct-to-consumer brands saw a significant increase in market share in 2017. According to a study carried out in 2017,90 percent of consumers prefer 
to buy directly from a brand if they have the option. This new strategy of direct marketing, selling directly to the consumer and bypassing traditional distribution networks, is changing the industry. Direct-to-consumer marketing is one of the main forces changing the industry right now. The fragmented, unconsolidated and highly competitive marketplace allows for smaller brands to utilize social media and digital, direct-to-consumer marketing strategies to break down traditional marketing and distribution barriers to entry. ${ }^{15}$

Early in 2020, e-commerce made up 22 percent of RMSC's sales, while 10 percent came from wholesale, and the majority of sales, 68 percent, came from retail. The ratio changed as physical retail operations were shut down during the 2020 Covid-19 pandemic. During the lock-down of the retail operations, RMSC's loyal customers raised its online sales by eight-fold. It will be interesting to see how this ratio stabilizes as retail operations gradually open up as the Covid-19 virus is brought under control during 2020-21.

The growth of business-to-business (B2B) e-commerce had also emerged in recent years and a study in 2016 concluded that almost half of Canadian B2B sellers generate 25 percent of their business online. A study in the United States suggests that B2B e-commerce will account for 1.2 trillion United States dollars by 2021, which is double the size of the American business-to-consumer e-commerce market. ${ }^{16}$ Interestingly, more than half of Canadian small businesses do not have an online presence to conduct sales, and shipping across the country can pose issues for smaller businesses. Small Canadian businesses also lose because more than 33 percent of Canadian consumer e-commerce transactions occur with American businesses. ${ }^{17}$ Currently, wholesale is not a big part of the business. Karina and Cam tend to think of wholesale or B2B as more of an awareness channel, where consumers who would not normally be exposed to their products get to test them out. A good example of this is their recent partnership with WestJet airline as the airline's soap provider.

RMSC has already done the work in prioritizing natural and toxin-free products, and has continued to research and innovate in this space. Because of this, the company does not need to change its business drastically to reflect changing consumer preferences for natural ingredients and environmental preservation, the way other existing businesses need to. However, the market is becoming increasingly saturated with healthier, toxin-free options and innovation is key to maintaining relevance and market share. RMSC is differentiating itself by prioritizing sustainability in every aspect of the business, but will need to continue to grow market share to compete with American brands that are permeating the Canadian market.

Lush, the Body Shop and Saje Wellness are RMSC's biggest competition in the Canadian market. These competitors also have brick-and-mortar stores in Canada. To the very astute customer, RMSC is the only one of those options 
that makes truly 100 percent natural products. However, most customers are less knowledgeable and liken the value proposition of these brands similarly to that of RMSC.

\section{ENVIRONMENTAL AND SOCIAL SUSTAINABILITY: CORE VALUE AND CORPORATE PURPOSE}

In Canada, the market for natural personal-care products is almost 1 billion Canadian dollars. At more than 10 percent annual growth, the Canadian market is growing at a slightly faster rate than the United States market. Consumers are looking for products that provide multiple benefits and are made from more natural ingredients. A study in Cosmetics Magazine indicated that the top three determinants of consumer trust are a company's ability to respond to issues and provide product information and transparency about how products are made. Canadian consumers are making smarter choices and holding companies to a higher standard than consumers in most other countries. ${ }^{18}$ This bodes well for an already transparent and responsible company like RMSC, but also means that other companies are beginning to rise to the occasion and address consumer demands. As these larger companies look for "greener" alternatives and regulations are slowly catching up in countries like Canada, consumers are also becoming more adept at spotting attempts to greenwash, that is, when a product or brand projects itself as more environmentally responsible than it truly is.

Part of what makes RMSC sustainable is its commitment to its values and purpose that is kept alive through strategic as well as operational decisions. From the ingredients in its products to the onboarding process, purpose is instilled in everything it does. The company values are quite literally written on the wall.

While RMSC measures and prioritizes environmental impact, Karina and Cam work hard to extend their impact to include the broader definition of sustainability, with a focus on community engagement and corporate social responsibility. Responsibility is embedded in the core of RMSC's business strategy and drives the purpose.

RMSC prioritizes sustainability in its physical spaces. Its workshop and stores are filled with recycled and eco-friendly materials. Salvaged and reclaimed wood make for excellent display cases. Marble, light fixtures and carpets, all reclaimed, create texture and character throughout the spaces. LED lights and low VOC paint are used for the most sustainable spaces. The corporate office and retail space in Canmore are powered by renewable energy by Bullfrog Power and rooftop solar panels. ${ }^{19}$ In the spirit of true transparency, tours of the Canmore-based factory are offered to the public to see how the products are made. These tours are equally popular with locals and tourists. 
Although the only mention of the tours is on the company's website and no advertising efforts are made, approximately 2,500 people take the tour annually, and several come back multiple times with family and friends.

Packaging is one of the more challenging areas in achieving the family's core values and corporate mission of sustainability. This is a challenge for all companies in the consumer packaged goods.

Most products, even natural ones, come packaged in plastic that is used once, and then sits in landfill for $100+$ years.

Karina and Cam acknowledge the gap that exists in the beauty industry between how long a product lasts and how long the packaging lasts. These concerns have troubled them since the inception of RMSC as they strongly believe that good-quality packaging does not have to be indestructible. Incremental adjustments have been made towards more sustainable packaging choices. Examples include updating soap recipes so there is no waste, using biodegradable edible packing peanuts instead of the more wasteful, non-biodegradable option, choosing recyclable or compostable packaging and reusing shipping boxes and materials. RMSC is also conscious of not using extra packaging, meaning that there are no extra boxes involved - no product inside of a box, inside of another box - a practice that is common amongst other consumer packaged goods brands. For example, according to RMSC, the cardboard that most personal-care products are surrounded by contributes to the loss of 18 million acres of forest each year. ${ }^{20}$ The commitment to sustainable packaging is clear when walking into any RMSC retail location. Most of the soap is presented without any packaging, and almost everything else has only one layer of packaging. The company follows its mantra of "what you see is what you get:"

Customers were saying for years that they wanted a refill program, so we put one in our Canmore store. As of now, not many people are using it. It's interesting because the usage of this program is less than the perceived demand. Customers feel good about us as a brand doing the refill program, but they are still buying off the shelf. That's what we're seeing, but are hoping that will slowly start to change. (Jane Doyle, Retail Director)

As it inches closer to the ambitious goal of eventually becoming a zero-waste company, the goal of diverting all waste from landfills is not easily achievable. More recently RMSC has attacked this issue head on becoming even more innovative with its packaging decisions. For example, its Lip Quench product container is completely biodegradable and it has launched recycled (non-virgin) plastic packaging. The physical appearance of more sustainable packaging poses an interesting dilemma as a recycled plastic bottle has a slight yellow tinge and is not as clear or transparent as traditional packaging. As consumers are used to purchasing products with attractive packaging, the larger and more influential consumer packaged goods product manufacturers 
have resisted such changes. Thus, RMSC and other environmentally conscious companies face an inherent risk in choosing more sustainable packaging as it may be less appealing to certain customers. Perseverance and commitment to innovation and sustainability is tested with every batch of product that leaves its manufacturing facility. The family's patient capital philosophy is evident in the risk that it is willing to take, as noted by Cam:

\section{We don't believe our products are truly natural if the packages are not $100 \%$ natural.}

RMSC has worked extensively with the Sustainable Packaging Coalition in the last six years on packaging options for its other products. This research indicated that paper is the most sustainable option, with post-consumer recycled plastic coming in second. Glass scored lower in many of the categories of research and generates more emissions in shipping due to weight. RMSC is currently working on switching over to the best plastic options, like using bio-based and post-consumer resins. It is also working to eliminate the need for most plastic by offering more refillable options as well as non-packaged options like shampoo bars (Figure 2.3):

An exciting newer sustainability initiative is the pilot returnable refill program. We have bins in stores where a customer can bring back their one liter bottles. We take those bottles, clean them, refurbish them and put them back on the shelf. People have really been supportive and have been buying the refurbished bottles. So currently, we are trying to figure out the details with this one liter program, work out the kinks, and roll out the same idea with other sized bottles. We're always rethinking sustainability in our packaging. (Cam Baty, COO)

In terms of production, the following sustainability principles are followed by RMSC when deciding on the ingredients in its products:

- Guaranteed to be found in nature and good for you.

- As organic and local as is available.

- Will not be produced or extracted through environmentally harmful processes.

- Will not have harmful impacts on your body.

The formulation and creation process for the products is taken seriously, and it often takes a few years to get a combination right. The formulas are designed by chemists and tested scientifically and extensively to ensure the best and safest product for consumers. RMSC products are never tested on animals, nor will the products harm natural habitats or aquatic life when they go down the drain and out into the environment. Not only does this require patience from the owners as coming up with usable products takes time and scientists must be 


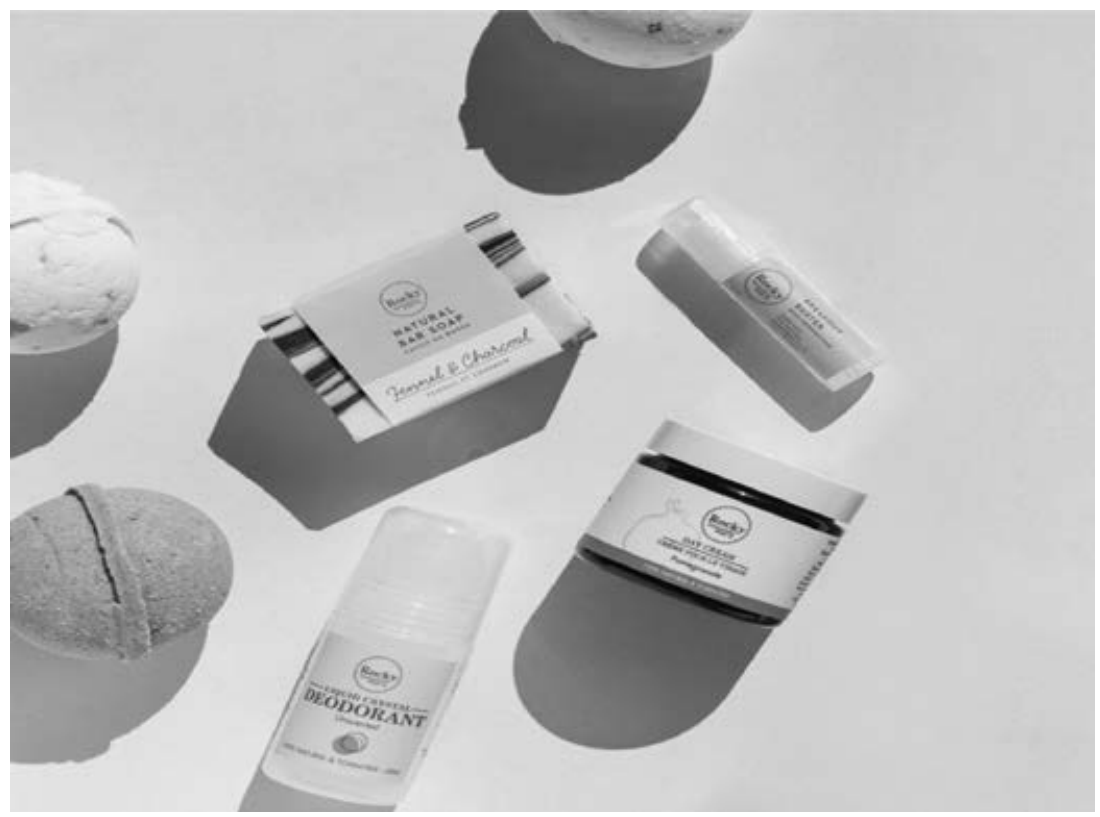

Figure 2.3 A sampling of RMSC products like bath bombs, lip balm and deodorant in different types of packaging

paid regularly, but there is an inherent risk of intellectual property theft. Cam explains the process and risks as follows:

We have IP [intellectual property] trademarks on our name and logo but there is no protection of our formulas. We have been so focused on getting them right and staying committed to our mission of natural.

The company is also doing its part to ensure consumers are educated about ingredients. On RMSC's website, there are two lists, the "Red List" and the "Green List," consisting of exactly what one would imagine lists with those names would contain - ingredients that are used in Rocky Mountain Soap products, and those that will never be used. Each of the "green" ingredients has an explanation of why it is used. Also available online is the company's "Naturalpedia," a platform where it shares its knowledge about fresh, natural ingredients and benefits. ${ }^{22}$ RMSC has yet to complete life-cycle analysis of the products. This may be something it considers as the product offerings grow and there is naturally less direct oversight and management of where the ingredients are coming from. 
RMSC's toxin-free community is a promotional program that customers can sign up for. By doing so, they receive free products and information about living a toxin-free life. Because of the toxin-free mission of the company, Karina has done some work with prominent and respected Canadian environmental protection non-governmental organizations such as the Suzuki Foundation and the Environmental Working Group. Elevating their toxin-free messaging is something Karina and Cam continue to consider as they look into the future of their business.

Along with sustainability strategies that protect the natural environment, RMSC is focused on promoting healthy and well-balanced lifestyles. Canmore is the focus of the company's social impact as Karina and Cam are proud to support the community they call home and in which their business is quite influential. For over 10 years, RMSC has organized The Rocky Mountain Soap Women's Run and Walk, an annual event that encourages safe, fun and inclusive events for women that inspire the pursuit of an active, healthy and environmentally responsible lifestyle:

It's inspiring to see how running brings women together and how many women's lives have been positively impacted by running. The Rocky Mountain Soap Women's Run is a testament to women and the power of running. The run was an incredible experience in a spectacular setting with amazing women! (Vera, Women's Run Participant)

The event builds a community platform that offers knowledge and expertise of wellness professionals and supports charitable organizations each year. Well-being stations are available at the post-race reception and RMSC is proud to sponsor this event every year creating an unforgettable experience for women of all ages and fitness levels. The event is widely attended, with people visiting Canmore from surrounding towns and cities, like Calgary, to participate. ${ }^{23}$

Aside from the clear environmental mission and this annual run event, Karina and Cam have implemented other corporate social responsibility initiatives as well. They sponsored a Canadian Olympian who competed in the biathlon in the most recent Olympic Games. Also, since 2015, the company has sent three staff members to communities in Liberia in Africa and India to teach soap making. The hope for these visits is to teach skills to help locals create business opportunities in communities in developing nations. As the company grows, there will be further opportunities to extend social impact.

\section{THE FUTURE}

Building trust with our customers - that is our focus. (Cam Baty, COO) 
There are obstacles that the business will need to overcome in the coming years. Karina and Cam have mentioned their intention to expand the scope of the leadership team to add an expert in larger-scale consumer packaged goods as a permanent leadership team member to help grow the business across Canada. They understand that better strategy needs to be in place to expand the brick-and-mortar stores, and bringing in someone with expertise would be a healthy first step:

In another ten years, I think the heart of the company will still be the bath and body products, though distribution channels may be changing. It will be interesting to see the market demand for natural products and how we react to it. It would be great to think that Cam and Karina's children might be involved in the business. Their oldest actually sat in on one of our strategic planning sessions, so the seed is being planted young. What I know is that Karina's passion for natural and toxin-free will continue to be the guiding light. (Jane Doyle, Retail Director)

With the increasing popularity of the direct-to-consumer market, especially in the personal-care industry, RMSC's leadership team recognizes the opportunity to expand the company's digital presence and create a more robust social media strategy. For example, currently, RMSC has about 30,000 followers on Instagram, in sharp contrast to the 220,000 followers of Saje Wellness, a direct competitor. ${ }^{24}$ As consumers increasingly continue to shop online, ${ }^{25}$ RMSC has an opportunity to expand its e-commerce presence and could consider expanding to retailers with broader online markets like Grove Collaborative or Sephora. As noted by Patrick Hemalal, the R\&D director:

The business will grow as the demand for natural products is growing. Premium sub-branding may happen as well - you never know. The market will grow and we will hopefully expand across Canada, the US and Europe.

As mentioned above, during the Covid-19 pandemic in 2020, as physical retail operations were shut down, online sales increased eight-fold, and it will be interesting to see how the ratio of physical retail sales and online sales stabilizes once the pandemic is brought under control. It is very likely that the ratio of online sales will stay much higher and continue to grow in the future.

Branding is a huge part of this challenge. As RMSC continues to grow, the leadership is reconsidering the branding of the company as a soap company. Right now, the company is somewhat limited by its name, as some consumers might hear "Rocky Mountain Soap Company" and make incorrect assumptions about what kind of products might be available there. The leadership is discussing the idea of keeping the flagship brand and expanding with sub-brands for hair and skin-care lines. Another option is a complete rebrand, though that would be a huge challenge to regain brand recognition with its 
existing customer base. Partnerships, certifications and advocacy work are all avenues that the leadership is exploring for the company's future and to expand RMSC's network.

The future is bright for RMSC. Twenty years ago, Karina and Cam bought a small failing company and entered a niche market. Now, green businesses are part of the mainstream in Canada and the United States. Innovation will continue to determine the company's path forward. RMSC chemists will continue to work on emerging technologies, and have hopes to discover new active molecules to be able to invent new plant-based formulas and products. There is a network of chemists in Canada working with local plants on the science of formulation and RMSC hopes to integrate even more local Canadian ingredients into its product lines. Karina and Cam aspire to enter new markets, and potentially develop sub-brands, beginning with the potential for an all-natural skin-care line and continuing the company's innovative work on a natural hand sanitizer:

I feel very lucky to work for Cam and Karina. I love that we are still growing and innovating and we won't settle. There's something amazing when you have a group of people that have the same belief, the same reasons why, and where that can take you. To be able to be challenged every day - I feel blessed to be a part of it. (Jane Doyle, Retail Director)

Taking a next-generation approach, Karina and Cam are eager to educate their children about the business, but are also supportive of their kids forging their own paths, just like they did. The future of this business being run by one of their kids is uncertain, though their oldest daughter has expressed interest in expanding her business education:

We are thinking about the future of the company, but aren't making a specific plan. Right now, our kids are interested in what we do, but we don't want to count on them wanting to run it. We want them to do what they want to do. We will see what happens! (Cam Baty, COO)

For now, Karina and Cam intend to continue in their leadership roles, spread the company's mission and help the business flourish even more. Who knows what the future will hold, but one thing is for certain, over the last 20 years, RMSC has developed into a sustainable family business with purpose and passion behind every step:

When I think about RMSC 10, 20 years down the line, I picture a successful expansion throughout Canada, maybe Asia and the US, with a strong online presence. I have hopes that we will still be based out of Canmore, and will still be a private company, run by family. Ultimately, our goal will still be to provide the best natural, toxin-free options to our customers. (Cam Baty, COO) 


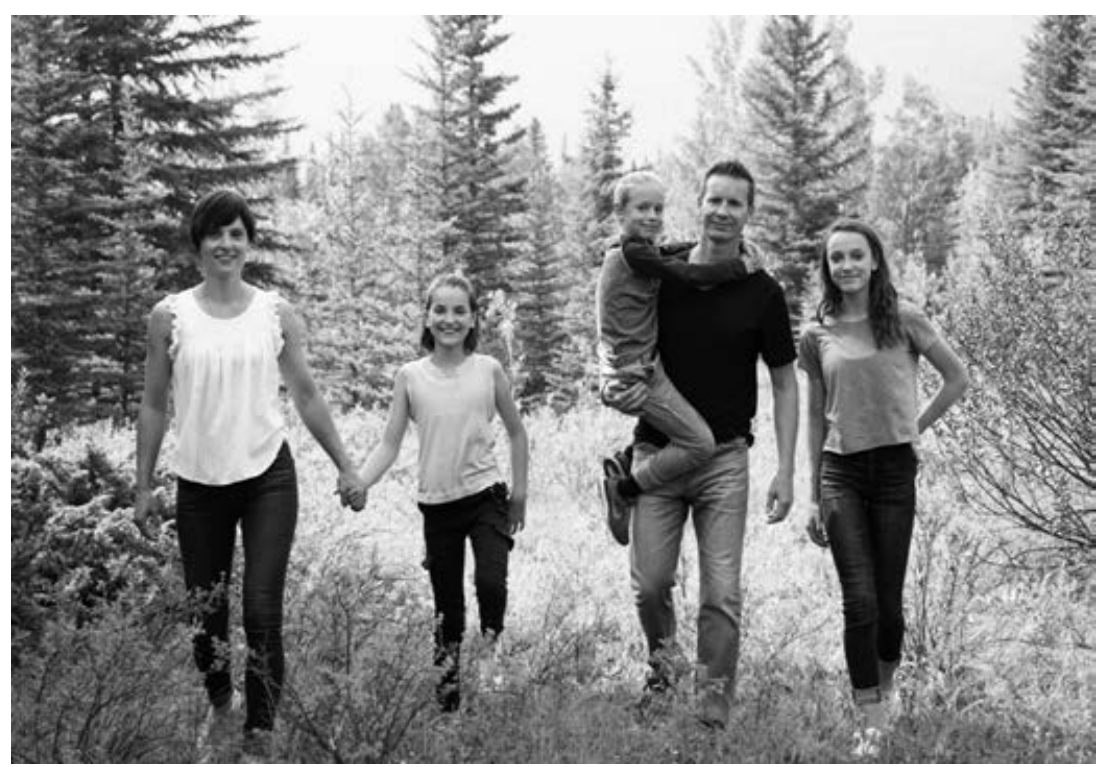

Figure 2.4 Karina and Cam with their three children

\section{CONCLUSION}

It is often argued that it is easier to start a sustainable company with a clean slate than it is to transform an existing company. While this argument has merit, the case of RMSC shows that even when a new business is started with core values and principles of sustainability, it is not an easy path and numerous difficult choices have to be made. Most of these choices involve sacrificing short-term profits and returns for patient investments in products, markets, educating consumers, supply chains and operations that pay off only in the long term - in the case of RMSC, its growth rates show that payoff has been above-industry averages. What keeps such businesses on the path is an unflagging and uncompromising commitment to its core values of sustainability - both environmental and social. Such commitment is more possible in family businesses because the business is an extension of the family values and not just a commercial operation, and they keep their eyes steadily on the future not only for the business, but as in the case of RMSC, for a toxin-free healthy community and society. This is the story of one such pioneering sustainable family business that exemplifies patient capital. 


\section{KEY INSIGHTS}

- Acquisition of a small venture with products aligned with sustainability beliefs of first-time entrepreneurs can provide the necessary foundation to build upon quickly.

- Environmental sustainability is more easily experienced in the natural environment and hence location of the business enables the family to bring environmental sustainability into the core missions and also attract employees with values to find solutions for environmental preservation.

- Internal physical spaces of an organization can be a powerful medium to simultaneously embed the sustainability values in an enterprise and display them externally as lived values.

- With each step integrating environmental and social sustainability principles into operations, it becomes possible for employees to identify the next challenges and explore viable solutions to remain on the path of continuous improvement. Such integration also reinforces employee values and innovativeness for social and environmental sustainability.

- As consumers become increasingly concerned and aware of environmental and social impacts of business operations, transparency of ingredients and activities is critical for gaining competitive advantage and customer loyalty for this segment.

- Social initiatives like the company's Women's Run and Walk help raise awareness about the values of the business and increase customer interest and loyalty toward its core business.

- Carefully planned sabbaticals by family founders that balance the autonomy and accountability of non-family employees can become potent tools to build internal leadership, organizational capabilities and culture.

\section{NOTES}

1. Bauer, E. (2017). Canadian Beauty Industry up by 9.4\%: News: NPD Canada. NPD Group. www.npdgroup.ca/wps/portal/npd/ca/news/press-releases/whats -fuelling-the-canadian-beauty-industry/

2. Serafeim, G. (2018). "Facebook, BlackRock, and the case for purpose-driven companies." Harvard Business Review, January 16.

3. Murray, G. (2020). Natural Vs Synthetic Beauty: Have We Got It All Wrong? Refinery29.com. www.refinery29.com/en-gb/2017/10/177954/synthetic-natural -beauty-ingredients

4. Delventhal, S. (2019). Study Shows Surge in Demand for "Natural" Products. Investopedia. www.investopedia.com/articles/investing/022217/study-shows-sur ge-demand-natural-products.asp

5. Ibid.

6. CB Insights Research (2018). 13 Trends Shaping the Face of Beauty in 2018. www.cbinsights.com/research/report/beauty-trends-2018/ 
7. Ibid

8. Rocky Mountain Soap (2020). Rocky Mountain Soap Company - 100\% Natural Skin Care. www.rockymountainsoap.com/

9. WestJet (2020). www.westjet.com

10. Lush (2020). www.lush.ca

11. Rocky Mountain Soap (2020). Rocky Mountain Soap Company - 100\% Natural Skin Care. www.rockymountainsoap.com/

12. Ibid.

13. Canmore.ca (2020). https://canmore.ca/

14. Well.ca (2020). https://well.ca/

15. CB Insights Research (2018). 13 Trends Shaping the Face of Beauty in 2018. www.cbinsights.com/research/report/beauty-trends-2018/

16. Digital Commerce 360 (2019). U.S. B2B E-commerce Is on Course to Hit $\$ 1.18$ trillion by 2021. www.digitalcommerce360.com/2017/06/05/u-s-b2b-e-commerce -course-hit-1-18-trillion-2021/

17. Ibid.

18. Behrendt, A. (2019). Sustainability Is Key in the Canadian Natural Personal Care Market. Kline \& Company. https://klinegroup.com/sustainability-is-key-in-the -canadian-natural-personal-care-market/

19. Rocky Mountain Soap (2020). Rocky Mountain Soap Company - 100\% Natural Skin Care. www.rockymountainsoap.com/

20. Ibid.

21. Ibid.

22. Ibid.

23. Ibid.

24. Instagram (2020) Rocky Mountain Soap Co. www.instagram.com/rocky mountainsoapco/

25. When this case was finalized the Covid-19 pandemic had engulfed the world. As with many countries, Canada had restricted travel and movement. All retail operations of RMSC were closed for several weeks, though the online sales had grown eight-fold. The leadership team was waiting to see if the increased online sales would continue once travel restrictions had lifted, and if so, whether retail operations would still remain viable. 